\title{
SLC7A11, a component of cysteine/glutamate transporter, is a novel biomarker for the diagnosis and prognosis in laryngeal squamous cell carcinoma
}

\author{
ZHIHONG MA ${ }^{1,4}$, HONG ZHANG ${ }^{1}$, MENG LIAN ${ }^{2}$, CHANGLI YUE ${ }^{1}$, GEHONG DONG ${ }^{1}$, YULAN JIN ${ }^{1}$, \\ RUI LI ${ }^{1}$, HONGFEI WAN $^{1}$, RU WANG $^{2}$, YING WANG ${ }^{2}$, JIE ZHAI $^{2}$, HONGZHI MA $^{2}$, LING FENG ${ }^{2}$, \\ JIANFENG HAN ${ }^{2}$, SHUZHOU LIU ${ }^{2}$, YOUXIN GUO ${ }^{4}$, JIANHUA LI $^{5}$, YU LIU ${ }^{6}$, \\ JUGAO FANG ${ }^{1-3 *}$ and HONGGANG LIU ${ }^{1 *}$
}

\begin{abstract}
${ }^{1}$ Department of Pathology, Beijing Key Laboratory of Head and Neck Molecular Diagnostic Pathology;
${ }^{2}$ Department of Otorhinolaryngology Head and Neck Surgery, Beijing Tongren Hospital, Capital Medical University,

Beijing 100730; ${ }^{3}$ Key Laboratory of Otorhinolaryngology Head and Neck Surgery, Ministry of Education, Beijing Institute of Otorhinolaryngology, Beijing 100005; Departments of ${ }^{4}$ Otolaryngology and ${ }^{5}$ Surgical Oncology, Chengde Central Hospital, Chengde, Hebei 067000; ${ }^{6}$ Department of Pathology, School of Basic Medical Sciences, Capital Medical University, Beijing 100730, P.R. China
\end{abstract}

Received January 22, 2017; Accepted July 14, 2017

DOI: $10.3892 / o r .2017 .5976$

\begin{abstract}
Solute carrier family 7, membrane 11 (SLC7A11) or $(\mathrm{xCT})$ is a component of the cysteine-glutamate transporter, which plays a critical role in glutathione homeostasis which is important to protect cells from oxidative stress. SLC7A11 is distributed in various tissues and participates in the occurrence of a number of diseases, particularly in the pathogenesis of malignant tumors, but its role in laryngeal cancer development has not yet been clearly defined. The objective of the present study was to investigate the role of SLC7A11 in laryngeal squamous cell carcinoma (LSCC). We conducted immunohistochemistry and RT-PCR to evaluate the protein and mRNA levels of SLC7A11 in LSCC and in control tissues, respectively. The knockdown experiments were conducted with SLC7A11 short hairpin RNA (shRNA) lentivirus, and
\end{abstract}

Correspondence to: Professor Honggang Liu, Department of Pathology, Beijing Key Laboratory of Head and Neck Molecular Diagnostic Pathology, Beijing Tongren Hospital, Capital Medical University, 1 Dongjiaominxiang Road, Dongcheng, Beijing 100730, P.R. China

E-mail: liuhg1125@163.com

Professor Jugao Fang, Department of Otorhinolaryngology Head and Neck Surgery, Beijing Tongren Hospital, Capital Medical University, 1 Dongjiaominxiang Road, Dongcheng, Beijing 100730, P.R. China E-mail: fangjg19651110@163.com

*Contributed equally

Key words: laryngeal squamous cell carcinoma, SLC7A11, Ki-67, p53, biomarker the protein and mRNA levels of SLC7A11 were assessed by RT-PCR and western blotting. The functional study of SLC7A11 in vitro was conducted by MTT assay, and the effects on the cell cycle were detected using flow cytometry. Immunohistochemical results revealed that the expression levels of SLC7A11, Ki-67 and p53 in LSCC tissues were higher than those in laryngeal dysplasia tissues. The Spearman rank correlation analysis revealed that the expression of SLC7A11 was positively correlated with the expression of p53 and Ki-67. Cox regression analysis and Kaplan-Meier plots confirmed that the expression levels of SLC7A11 were a prognostic factor for overall survival (OS) rates and postoperative recurrence of LSCC. Moreover, the functional study of SLC7A11 in vitro revealed that knockdown of SLC7A11 using shRNA inhibited cell proliferation by inducing cell cycle arrest at the G1 phase. Immunohistochemical and RT-PCR results and knockdown experiments of SLC7A11 revealed that SLC7A11 was involved in the progression of LSCC, and may provide clinical information for the evaluation of OS rates and postoperative recurrence of LSCC. Collectively, these observations suggest that SLC7A11 may be a vital biomarker for the diagnosis and prognosis in human LSCC, and targeting SLC7A11 appears to be a potentially significant method for LSCC treatment.

\section{Introduction}

Laryngeal squamous cell carcinoma (LSCC) is a common type of malignant tumor of the head and neck and is the second most common reason for cancer-related deaths and poor prognosis among malignancies in the respiratory tract (1). Current treatments, including surgical resection, radiation therapy and chemotherapy, have already had a good curative effect on early stage cases, but are less effective in more advanced cases $(2,3)$. Although LSCC patients have to bear complete or partial loss 
of vocal function due to laryngectomy, and many patients have to endure a tracheal cannula throughout their lives due to a total laryngectomy, an increased local recurrence rate and lower OS rates have been witnessed over the past decades (4). Therefore, a comprehensive understanding of the molecular mechanisms of LSCC progression and findings of novel molecular markers for the diagnosis and prognostic assessment of LSCC are in urgent demand.

Solute carrier family 7, membrane 11 (SLC7A11) or xCT, is a type of amino-acid transporter which is responsible for transporting cystine into cells in exchange for glutamate at a ratio of 1:1 (5). Amino-acid transporters are necessary for tumor cell growth and proliferation. In addition, SLC7A11-mediated cystine transport for GSH synthesis plays a key role in the prevention of oxidative stress signaling that is strongly associated with cell proliferation and tumor growth (6). Oxidative stress is mainly generated in cancer cells due to their relatively high metabolic rate $(7,8)$. Thus, the activity of SLC7A11-mediated cystine uptake for GSH synthesis in cancer cells is strongly associated with cell proliferation and tumor growth $(6,9)$. SLC7A11 has been demonstrated to be involved in a variety of human carcinomas, including glioma, breast, ovarian, colon, pancreatic, gastric and esophageal cancer (6,10-16). Although these studies suggest that the modulation of SLC7A11 activity is an intriguing strategy for the diagnosis, prognosis and therapy of cancer, the detailed mechanisms by which SLC7A11 regulates the proliferation in human LSCC have not been fully investigated. Furthermore, the clinicopathological impact of SLC7A11 expression on LSCC has remained elusive to date.

To determine whether SLC7A11 can be used as a biomarker in the diagnosis and prognosis of LSCC as well as the role of SLC7A11 in LSCC, we examined the expression of SLC7A11, $\mathrm{Ki}-67$ and p53 in paraffin-embedded laryngeal squamous carcinoma tissues by immunohistochemistry (IHC), and investigated the statistical relationships of the aforementioned three proteins. Then, we analyzed the relationship of SLC7A11 expression levels with clinicopathological characteristics such as OS and recurrence-free survival (RFS) rates in LSCC patients. SLC7A11 mRNA expression was further examined using RT-PCR in LSCC tissues and in para-cancerous tissues. Moreover, the human laryngeal cancer cell line Hep-2 and UMCC-5 were used to assess the effects of SLC7A11 in the cell proliferation process and the cell cycle. Our results indicate that SLC7A11 plays an important role in the tumor progression of LSCC.

\section{Materials and methods}

Tissue samples and patients. All specimens were obtained from the Beijing Tongren Hospital, including paraffinembedded and fresh tissues. Cases (327) of paraffin-embedded laryngeal squamous carcinoma tissues (including a recurrence group of 116 cases and a non recurrence group of 211 cases) as well as 108 cases of paraffin-embedded laryngeal atypical hyperplasia tissues and 62 cases of vocal polyp tissues, which were collected between August 2000 and November 2012 for immunohistochemical analysis. Another 30 cases of fresh tumor tissues and para-cancerous tissues, which were used for RT-PCR analysis, were randomly collected from LSCC patients between June 2013 and August 2014 and frozen at $-80^{\circ} \mathrm{C}$ until RNA extraction. Para-cancerous tissues were obtained directly after surgery from the surgery safety margin (0.5-1.0 $\mathrm{cm}$ beyond the tumor). All patients were confirmed clinically and histologically by laryngoscopy, CT, MRI and pathologic biopsy. The patient eligibility criteria were as follows: no synchronous or metachronous cancers (in addition to the LSCC) and no preoperative chemotherapy or radiation therapy. We excluded the patients with non-curative resected tumors or non-consecutive data. All patients had signed written informed consent. Ethical approval was provided by the Medical Ethics Committee of Beijing Tongren Hospital and was consistent with the Declaration of Helsinki.

The main experimental reagents. The anti-SLC7A11 antibody produced in rabbits was purchased from Abcam Biotechnology (Cambridge, UK) (1:500). Monoclonal anti-Ki-67 and monoclonal anti-p53 antibodies, and an IHC kit were purchased from Zhongshan Golden Bridge Biotechnology (Beijing, China). The rabbit or mouse negative control serum were purchased from Sigma Chemicals (St. Louis, MO, USA). RNeasy Mini kit and MTT assay were purchased from Beyotime (Shanghai, China). SLC7A11 short hairpin RNA (shRNA) and control shRNA lentiviruses were designed and synthesized by Hanbio Biotechnology (Shanghai, China). Antibiotic solution (104 U penicillin, $10 \mathrm{mg}$ streptomycin, $25 \mu \mathrm{g}$ amphotericin $\mathrm{B}$ ), dimethyl sulfoxide (DMSO), and propidium iodide (PI) were purchased from Sigma Chemicals. Fetal bovine serum (FBS) and Dulbecco's modified Eagle's medium (DMEM) were purchased from Gibco (Cambrex, MD, USA). Polyvinylidene difluoride (PVDF) membranes were purchased from Millipore (Bedford, MA, USA).

IHC. The archival paraffin-embedded tissue blocks were cut into $4-\mu \mathrm{m}$ thick tissue sections. The sections were deparaffinized with xylene and rehydrated by a graded ethanol series. Blocking of endogenous peroxidases was accomplished by incubating sections in 3\% hydrogen peroxide for $10 \mathrm{~min}$. Antigen retrieval was performed using Heat Processor Solution (pH 6) (Zhongshan Biotechnology, Beijing, China) at $125^{\circ} \mathrm{C}$ for 5 min by a pressure cooker, and then sections were cooled to room temperature. Goat blood serum (10\%) was used to prevent non-specific binding. Then, the sections were incubated with SLC7A11 purified polyclonal antibody, monoclonal anti-Ki-67 and monoclonal anti-p53 overnight at $4^{\circ} \mathrm{C}$, followed by incubation with the secondary antibody. Immunostaining was performed using two-step diaminobenzidine visualization. Sections were counterstained with hematoxylin, rinsed in water, dehydrated in ascending concentrations of ethanol followed by clearance with xylene, and cover slipped permanently for light microscopy. Negative controls were carried out with the same procedure using the rabbit or mouse negative control serum instead of the primary antibody. Repeatedly validated esophageal adenocarcinoma specimens with positive staining of SLC7A11 served as positive controls. Liver cancer and pulmonary squamous cell carcinoma tissues were applied as the positive control to indicate Ki-67 and p53 expression, respectively.

Evaluation of immunohistochemical variables. By IHC analysis of 327 laryngeal tissues, we found that the positive 
Table I. Immunohistochemical staining and scoring.

\begin{tabular}{lclccc}
\hline $\begin{array}{l}\text { Proportion of positive } \\
\text { tumor cells (\%) }\end{array}$ & Score 1 & $\begin{array}{c}\text { Average intensity } \\
\text { of positive tumors }\end{array}$ & Score 2 & \multicolumn{2}{c}{$\begin{array}{c}\text { Final score } \\
\text { (score 1+ score 2) }\end{array}$} \\
\hline$<10$ & 0 & Negative & 0 & 0 & Negative \\
$10-25$ & 1 & Pale yellow & 1 & $1-2$ & Weak positive \\
$26-75$ & 2 & Yellow & 2 & $3-5$ & Positive \\
$>76$ & 3 & Dark yellow or & 3 & $6-7$ & Strong positive \\
\hline
\end{tabular}

staining of the SLC7A11 protein expression was chiefly located in the membrane of the parabasal cell layer and epithelial cells, and the positive staining of p53 and Ki-67 proteins were mainly located in the nuclei of epithelial cells (Fig. 1). Two independent investigators who were blinded to all immunohistochemical outcomes, adopted a semi-quantitative system with the staining intensity and proportion to scored all specimens. Five microscopic fields in tumor tissues (original magnification, x400) were randomly selected. According to the color of the staining, immunohistochemical results were divided into no staining (with the same color as the background), low staining (with a color slightly stronger than the background), middle staining (with a color markedly stronger than the background), and high staining. Each rate got a score of $0,1,2$ and 3, respectively. According to the percentage of the positive cells in the field, $<10 \%$, between $10-25 \%, 26-75 \%$ and $>76 \%$ were scored as $0,1,2$ and 3 , respectively. Then, these two values were combined to determine the protein expression of each group (the final score 0-2 represented negative '-' staining, the final score 3-7 represented positive ' + ' staining). The counting method is shown in (Table I).

$R T$-PCR. Thirty cases of fresh LSCC and the corresponding pericarcinomatous tissues were collected, and three cases were separately randomized into a single sample. The SLC7A11 gene mRNA sequences were acquired from the NCBI database to design an RT-PCR primer. The sequences of the primer pairs were: forward, 5'-CATCTCTCCTAAGGGC GTGC-3' and reverse, 5'-CCCACGAGAGAAAAAGTCG-3'. Total RNA was extracted using TRIzol reagent, and reverse transcribed to complementary DNA (cDNA) using an RT-PCR kit (Gibicol) according to the manufacturer's recommendations. PCR reactions were incubated at $94^{\circ} \mathrm{C}$ for $3 \mathrm{~min}$, followed by 30 cycles of $94^{\circ} \mathrm{C}$ for $30 \mathrm{sec}, 57^{\circ} \mathrm{C}$ for $40 \mathrm{sec}, 70^{\circ} \mathrm{C}$ for $50 \mathrm{sec}$, and then a final extension at $72^{\circ} \mathrm{C}$ for $10 \mathrm{~min}$. GAPDH was used as an internal control using the relative quantification method. All assays were performed in triplicate.

Cell culture. The human LSCC cell line UMCC-5 was gifted by the Cell Bank of the University of Michigan (Ann Arbor, MI, USA). The human LSCC cell line Hep-2 was purchased from the China Infrastructure of Cell Line Resources. All cells were maintained in DMEM supplemented with $10 \%$ FBS and penicillin/streptomycin at $37^{\circ} \mathrm{C}$ in a humidified atmosphere of $5 \% \mathrm{CO}_{2}$. The cells were split twice weekly and cells in the logarithmic growth phase were used for experiments.
Construction of SLC7A11-shRNA lentivirus and establishment of stable transfectants. SLC7A11-shRNAs (shRNA1, shRNA2 and shRNA3) and a negative control-shRNA (NC-shRNA) lentivirus were designed and synthesized by Hanbio Biotechnology. The oligonucleotide sequences of SLC7A11-shRNA1 were: 5'-GAGTCTGGGTGGAACTCCT CATAAT-3'; the oligonucleotide sequences of SLC7A11shRNA2 were: 5'-CCCTGGAGTTATGCAGCTAAT-3'; the oligonucleotide sequences of SLC7A11-shRNA3 were: 5'-GGT GTGTTTGCTGTCTCCAGGTTAT-3'; the oligonucleotide of control-shRNA was: 5'-TTCTCCGAACGTGTCACGTAA-3'. Hep-2 and UMCC-5 cells were cultured in growth medium to reach confluency of 60-80\%, and then, were respectively transfected with $50 \mathrm{nmol} / 1$ SLC7A11-shRNA1 or SLC7A11-shRNA2 or SLC7A11-shRNA3 or NC-shRNA using Lipofectamine 2000 according to the manufacturer's instructions (10). At 48-96 h after transfection, the cells were collected for the following assays. Luciferase-reporter assays, RT-PCR and western blotting were used to illustrate the transfection efficiency of sh-SLC7A11 in UMCC-5 and Hep-2 cells. Independent triplicate wells were used for each vector.

Western blot analysis. UMCC-5 and Hep-2 cells were cultured and infected with recombinant lentivirus for four to five days, and then the proteins of collected cells were lysed with 2X SDS sample buffer [100 mM Tris- $\mathrm{HCl}$ (pH 6.8), $10 \mathrm{mM}$ EDTA, 4\% SDS, $10 \%$ glycine]. Protein $(20 \mu \mathrm{g})$ was loaded onto a $10 \%$ SDS-PAGE and transferred to a PVDF membrane. Next, antibodies against SLC7A11 (1:200; Abcam) or GAPDH (1:300; Bioworld Technology, Minneapolis, MN, USA) were used as the primary antibodies. The detection was performed using an ECL kit. Bands on X-ray films were quantified with an ImageQuant densitometric scanner (Molecular Dynamics, Sunnyvale, CA, USA). Each experiment was repeated three times.

Flow cytometric assay. The Hep-2 and UMCC-5 cells were harvested $72 \mathrm{~h}$ after transfection with either SLC7A11-shRNA or control-shRNA. After trypsinization, the supernatant was discarded and the cells were collected and washed with phosphate-buffered saline (PBS), and then fixed with $1 \mathrm{ml}$ ice-cold $70 \%$ alcohol. Following incubation at $4^{\circ} \mathrm{C}$ for at least $12 \mathrm{~h}$, the cells were washed with PBS and stained with $50 \mu \mathrm{l} / \mathrm{ml}$ PI (Sigma) solution and supplemented with $100 \mu \mathrm{l} / \mathrm{ml}$ RNase in PBS, and incubated sequentially in the dark at room temperature for $30 \mathrm{~min}$. The cell cycle analysis of samples were analyzed immediately using flow cytometry 

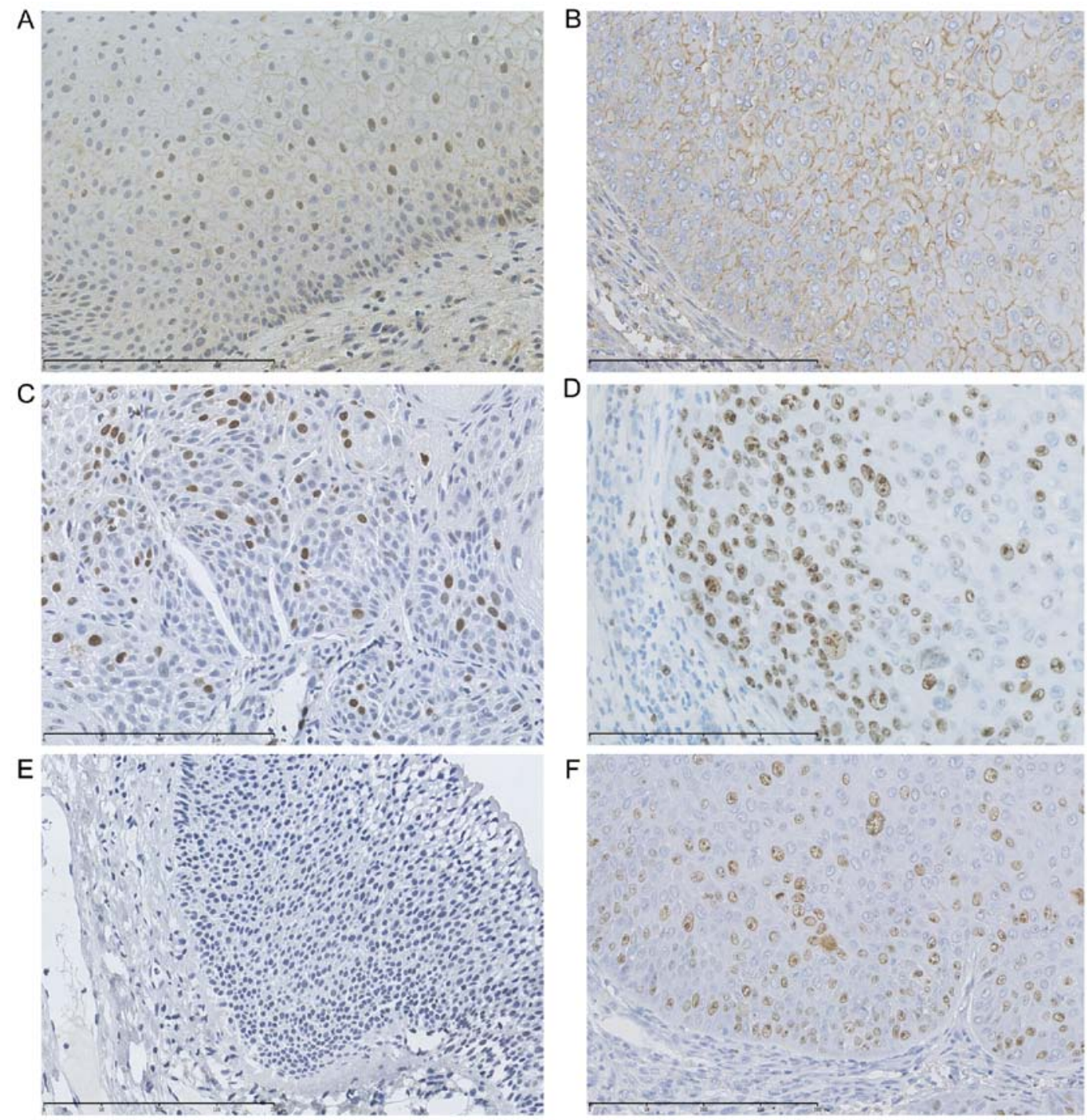

Figure 1. Immunohistochemical staining of SLC7A11, Ki-67 and p53 proteins in laryngeal atypical hyperplasias and LSCC tissues. (A, C and E) Immunohistochemical staining of human laryngeal atypical hyperplasias tissues with SLC7A11, Ki-67 and p53 antibodies, respectively. (B, D and F) Immunohistochem ical staining with SLC7A11, Ki-67 and p53 antibodies for human LSCC. Marked staining of the SLC7A11 protein was mainly found in the membrane of the carcinoma cells (B). (D and F) Brown positive staining of the Ki-67 and p53 proteins were clearly identified in the nucleus of the carcinoma cells. (A-D and F) Original magnification, x400. (E) Original magnification, x200.

(FACSCalibur; BD Biosciences, Franklin Lakes, NJ, USA) according to the manufacturer's protocol as previously described (17). Each experiment was performed in triplicate and repeated three times. The percentage of cells in the G0/G1, $\mathrm{S}$ and $\mathrm{G} 2 / \mathrm{M}$ phases were determined using CellQuest software (version 3.3; BD Biosciences).

MTT cell proliferation. Cell proliferation was determined by MTT assay after $0,24,48,72$ and $96 \mathrm{~h}$ of lentiviral transfection. Cells were seeded into 96-well culture plates at a concentration of 3,000 cells/well and each well was incubated with $20 \mu \mathrm{l}$ of MTT solution for $4 \mathrm{~h}$ at $37^{\circ} \mathrm{C}$ and $5 \% \mathrm{CO}_{2}$. Subsequently, the medium was aspirated, and the resulting purple formazan crystals were dissolved in DMSO (18). The absorbance at $490 \mathrm{~nm}$ was determined using a microplate reader. Experiments were performed in triplicate using an MTT assay following the manufacturer's instructions. Cell viability was expressed as a percentage of the control culture and the $\mathrm{IC}_{50}$ values were calculated from non-linear regression using the program GraphPad Prism 5.0 software (GraphPad Software,. Inc., La Jolla, CA, USA).

Statistical analysis. Statistical analysis was performed using SPSS 20.0 software. The Chi-square or Fisher's exact tests were used to evaluate the association between the expression levels of SLC7A11 and the clinicopathological characteristics. The Wilcoxon-Mann-Whitney test was used to evaluate the messenger RNA levels of SLC7A11 in laryngeal carcinoma and the adjacent tissues. The Spearman rank correlation was used to evaluate the correlation between SLC7A11, p53 and Ki-67. Survival curves were constructed by the Kaplan-Meier method, and the survival differences were examined using the log-rank test. A multivariate analysis of factors influencing survival was performed using the Cox proportional hazards model. The Student's t-test was used to evaluate the differences between the SLC7A11 knockdown and the control cells. $\mathrm{P}<0.05$ was considered to indicate a statistically significant result. 
Table II. Relationship between the expression of SLC7A11 and the clinicopathological parameters in laryngeal cancer patients.

\begin{tabular}{|c|c|c|c|c|}
\hline $\begin{array}{l}\text { Clinico- } \\
\text { pathological } \\
\text { parameters }\end{array}$ & $\begin{array}{l}\text { No. } \\
\text { of } \\
\text { cases }\end{array}$ & $\begin{array}{c}\text { SLC7A11 } \\
\text { immunostaining } \\
\text { high expression } \\
\text { frequency } \\
(\%)\end{array}$ & $\chi^{2}$ & P-value \\
\hline Vocal polyp & 62 & $21(33.9)$ & 8.558 & $0.003^{\mathrm{a}}$ \\
\hline $\begin{array}{l}\text { Laryngeal } \\
\text { atypical } \\
\text { hyperplasia }\end{array}$ & 108 & $46(42.6)$ & 4.324 & $0.038^{b}$ \\
\hline LSCC & 327 & $177(54.1)$ & & \\
\hline \multicolumn{5}{|l|}{ Age (years) } \\
\hline $\begin{array}{l}\leq 65 \\
>65\end{array}$ & $\begin{array}{l}184 \\
143\end{array}$ & $\begin{array}{r}107(58.1) \\
70(48.9)\end{array}$ & 2.744 & 0.098 \\
\hline \multicolumn{5}{|l|}{ Sex } \\
\hline $\begin{array}{l}\text { Male } \\
\text { Female }\end{array}$ & $\begin{array}{r}318 \\
9\end{array}$ & $\begin{array}{r}175(55.0) \\
2(28.6)\end{array}$ & 3.794 & 0.292 \\
\hline \multicolumn{5}{|l|}{ T stage } \\
\hline $\begin{array}{l}\mathrm{T} 1-\mathrm{T} 2 \\
\mathrm{~T} 3-\mathrm{T} 4\end{array}$ & $\begin{array}{l}207 \\
120\end{array}$ & $\begin{array}{l}99(47.8) \\
78(65.0)\end{array}$ & 9.023 & 0.003 \\
\hline \multicolumn{5}{|l|}{$\begin{array}{l}\text { Lymph node } \\
\text { metastasis }\end{array}$} \\
\hline $\begin{array}{l}\mathrm{N} 0 \\
\mathrm{~N}_{\mathrm{X}}\end{array}$ & $\begin{array}{r}237 \\
90\end{array}$ & $\begin{array}{r}121(51.1) \\
56(62.2)\end{array}$ & 1.031 & 0.31 \\
\hline \multicolumn{5}{|l|}{$\begin{array}{l}\text { Distant } \\
\text { metastasis }\end{array}$} \\
\hline $\begin{array}{l}\text { M0 } \\
\mathrm{M}_{\mathrm{X}}\end{array}$ & $\begin{array}{r}292 \\
35\end{array}$ & $\begin{array}{r}159(54.5) \\
18(51.4)\end{array}$ & 0.115 & 0.734 \\
\hline \multicolumn{5}{|l|}{$\begin{array}{l}\text { Tumor } \\
\text { differentiation }\end{array}$} \\
\hline $\begin{array}{l}\text { Highly } \\
\text { differentiated }\end{array}$ & 160 & $96(60.0)$ & 4.368 & 0.113 \\
\hline $\begin{array}{l}\text { Moderately } \\
\text { differentiated }\end{array}$ & 125 & $61(48.8)$ & & \\
\hline $\begin{array}{l}\text { Poorly } \\
\text { differentiated }\end{array}$ & 42 & $20(47.6)$ & & \\
\hline
\end{tabular}

${ }^{a}$ Compared with the vocal polyp tissue group. ${ }^{b}$ Compared with the laryngeal atypical hyperplasia group. LSCC, laryngeal squamous cell carcinoma; SLC7A11, solute carrier family 7, membrane 11.

\section{Results}

Association of the immunohistochemical expression of SLC7A11, Ki-67 and p53 with clinicopathological features. The IHC results confirmed that the protein expression levels of SLC7A11 were higher in the LSCC tissues than in the vocal polyp and laryngeal atypical hyperplasia tissues according to the Chi-square test $\left(\chi^{2}=8.558, \mathrm{P}=0.003 ; \chi^{2}=4.324\right.$, $\mathrm{P}=0.038$ ) (Table II and Fig. 1). When comparing the difference in the expression levels SLC7A11 according to T stages
Table III. Relationship between the expression of Ki-67 and the clinicopathological parameters in laryngeal cancer patients.

\begin{tabular}{|c|c|c|c|c|}
\hline $\begin{array}{l}\text { Clinico- } \\
\text { pathological } \\
\text { parameters }\end{array}$ & $\begin{array}{l}\text { No. } \\
\text { of } \\
\text { cases }\end{array}$ & $\begin{array}{c}\text { Ki-67 } \\
\text { immunostaining } \\
\text { high expression } \\
\text { frequency } \\
(\%)\end{array}$ & $\chi^{2}$ & P-value \\
\hline Vocal polyp & 62 & $17(27.4)$ & 8.190 & $0.004^{\mathrm{a}}$ \\
\hline $\begin{array}{l}\text { Laryngeal } \\
\text { atypical } \\
\text { hyperplasia }\end{array}$ & 108 & $38(35.2)$ & 4.670 & $0.031^{\mathrm{b}}$ \\
\hline LSCC & 327 & $154(47.1)$ & & \\
\hline \multicolumn{5}{|l|}{ Age (years) } \\
\hline$\leq 65$ & 184 & $85(46.2)$ & 1.595 & 0.207 \\
\hline$>65$ & 143 & $69(48.2)$ & & \\
\hline \multicolumn{5}{|l|}{ Sex } \\
\hline Male & 318 & $151(47.5)$ & 0.703 & 0.402 \\
\hline Female & 9 & $3(33.3)$ & & \\
\hline \multicolumn{5}{|l|}{ T stage } \\
\hline T0-T2 & 207 & $86(41.5)$ & 6.971 & 0.08 \\
\hline T3-T4 & 120 & $61(56.7)$ & & \\
\hline \multicolumn{5}{|l|}{$\begin{array}{l}\text { Lymph node } \\
\text { metastasis }\end{array}$} \\
\hline N0 & 237 & $117(49.4)$ & 1.784 & 0.182 \\
\hline $\mathrm{N}_{\mathrm{X}}$ & 90 & $37(41.1)$ & & \\
\hline \multicolumn{5}{|l|}{$\begin{array}{l}\text { Distant } \\
\text { metastasis }\end{array}$} \\
\hline M0 & 292 & $131(44.9)$ & 0.173 & 0.677 \\
\hline MX & 35 & $17(48.6)$ & & \\
\hline \multicolumn{5}{|l|}{$\begin{array}{l}\text { Tumor } \\
\text { differentiation }\end{array}$} \\
\hline $\begin{array}{l}\text { Highly } \\
\text { differentiated }\end{array}$ & 160 & $81(50.6)$ & 1.584 & 0.453 \\
\hline $\begin{array}{l}\text { Moderately } \\
\text { differentiated }\end{array}$ & 125 & $55(44.0)$ & & \\
\hline $\begin{array}{l}\text { Poorly } \\
\text { differentiated }\end{array}$ & 42 & $18(42.9)$ & & \\
\hline
\end{tabular}

${ }^{\mathrm{a} C o m p a r e d ~ w i t h ~ t h e ~ v o c a l ~ p o l y p ~ t i s s u e ~ g r o u p . ~}{ }^{\mathrm{b}}$ Compared with the laryngeal atypical hyperplasia group. LSCC, laryngeal squamous cell carcinoma.

of LSCC, we found that there were significant differences between T1-2 and T3-4. However, no statistical difference was found between LSCC patients with different ages, sex, lymph node and distant metastases, or tumor differentiation (Table II). Therefore, these data clearly indicated that SLC7A11 was increased in LSCC tissues and revealed that it may be a diagnostic marker for LSCC.

In order to investigate which SLC7A11-related proteins may be involved in the proliferation of LSCC, Ki-67 and p53 protein expression levels were evaluated by immunochemistry. The protein expression levels of $\mathrm{Ki}-67$ and p53 were also higher in 
Table IV. Relationship between the expression of p53 and the clinicopathological parameters in laryngeal cancer patients.

\begin{tabular}{|c|c|c|c|c|}
\hline $\begin{array}{l}\text { Clinico- } \\
\text { pathological } \\
\text { parameters }\end{array}$ & $\begin{array}{l}\text { No. } \\
\text { of } \\
\text { cases }\end{array}$ & $\begin{array}{c}\text { p53 } \\
\text { immunostaining } \\
\text { high expression } \\
\text { frequency } \\
(\%)\end{array}$ & $\chi^{2}$ & P-value \\
\hline Vocal polyp & 62 & $9(14.5)$ & 5.028 & $0.025^{\mathrm{a}}$ \\
\hline $\begin{array}{l}\text { Laryngeal } \\
\text { atypical } \\
\text { hyperplasia }\end{array}$ & 108 & $24(22.2)$ & 4.747 & $0.029^{b}$ \\
\hline LSCC & 327 & $92(28.1)$ & & \\
\hline \multicolumn{5}{|l|}{ Age (years) } \\
\hline $\begin{array}{l}\leq 65 \\
>65\end{array}$ & $\begin{array}{l}184 \\
143\end{array}$ & $\begin{array}{l}59(32.1) \\
33(23.1)\end{array}$ & 3.215 & 0.073 \\
\hline \multicolumn{5}{|l|}{ Sex } \\
\hline $\begin{array}{l}\text { Male } \\
\text { Female }\end{array}$ & $\begin{array}{r}318 \\
9\end{array}$ & $\begin{array}{r}91(28.6) \\
1(11.1)\end{array}$ & 0.602 & 0.438 \\
\hline \multicolumn{5}{|l|}{ T stage } \\
\hline $\begin{array}{l}\text { T0-T2 } \\
\text { T3-T4 }\end{array}$ & $\begin{array}{l}207 \\
120\end{array}$ & $\begin{array}{l}51(24.6) \\
41(34.2)\end{array}$ & 3.411 & 0.065 \\
\hline \multicolumn{5}{|l|}{$\begin{array}{l}\text { Lymph node } \\
\text { metastasis }\end{array}$} \\
\hline $\begin{array}{l}\mathrm{N} 0 \\
\mathrm{~N}_{\mathrm{X}}\end{array}$ & $\begin{array}{r}237 \\
90\end{array}$ & $\begin{array}{l}71(29.9) \\
21(23.3)\end{array}$ & 1.416 & 0.234 \\
\hline \multicolumn{5}{|l|}{$\begin{array}{l}\text { Distant } \\
\text { metastasis }\end{array}$} \\
\hline $\begin{array}{l}\text { M0 } \\
\mathrm{M}_{\mathrm{X}}\end{array}$ & $\begin{array}{r}292 \\
35\end{array}$ & $\begin{array}{r}85(29.1) \\
7(20.0)\end{array}$ & 1.283 & 0.257 \\
\hline \multicolumn{5}{|l|}{$\begin{array}{l}\text { Tumor } \\
\text { differentiation }\end{array}$} \\
\hline $\begin{array}{l}\text { Highly } \\
\text { differentiated }\end{array}$ & 160 & $40(25.0)$ & 2.866 & 0.239 \\
\hline $\begin{array}{l}\text { Moderately } \\
\text { differentiated }\end{array}$ & 125 & $36(28.8)$ & & \\
\hline $\begin{array}{l}\text { Poorly } \\
\text { differentiated }\end{array}$ & 42 & $16(38.1)$ & & \\
\hline
\end{tabular}

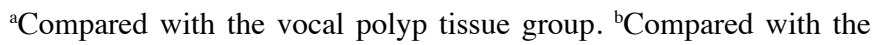
laryngeal atypical hyperplasia group. LSCC, laryngeal squamous cell carcinoma; SLC7A11, solute carrier family 7, membrane 11.

the LSCC tissues than in the vocal polyp and laryngeal atypical hyperplasia tissues (Tables III and IV). The Spearman rank correlation analysis revealed that the expression of SLC7A11 had a positive correlation with the expression of p53 and Ki-67, respectively (Table V). Meanwhile, the expression of Ki-67 and p53 also had a positive correlation with each other (Table V). These data demonstrated that Ki-67, p53 and SLC7A11 in LSCC may influence each other.

SLC7A11 gene mRNA expression levels in clinical tissue samples detected by real-time PCR. SLC7A11 mRNA levels
Table V. The correlation of SLC7A11 with Ki-67 and p53 expression in laryngeal cancer.

\begin{tabular}{lcc}
\hline & SLC7A11 & p53 \\
\hline SLC7A11 & 1 & \\
Correlation coefficient & 327 & $0.171^{\mathrm{a}}$ \\
Sig. (two-tailed) & & 0.002 \\
$\mathrm{~N}$ & & 327 \\
Ki-67 & $0.155^{\mathrm{a}}$ & $0.180^{\mathrm{a}}$ \\
Correlation coefficient & 0.005 & 0.001 \\
Sig. (two-tailed) & 327 & 327 \\
N & & \\
\hline
\end{tabular}

Significance is indicated at $\mathrm{P}<0.05$ or $\mathrm{P}<0.01$, thus showing that there is a statistically significant correlation. ${ }^{\mathrm{a}}$ Correlation is significant at a level of $<0.01$ (two-tailed). SLC7A11, solute carrier family 7 , membrane 11; Sig., significance.

Table VI. Multivariate analyses by Cox regression for recurrence-free survival of the postoperative LSCC patients.

\begin{tabular}{lcccc}
\hline & & & \multicolumn{2}{c}{$\begin{array}{r}\text { 95\% CI for } \\
\text { Exp (B) }\end{array}$} \\
\cline { 4 - 5 } Characteristics & Sig. & Exp (B) & Lower & Upper \\
\hline Sex & 0.056 & 2.451 & 0.978 & 6.139 \\
Age (years) & 0.566 & 0.904 & 0.64 & 1.277 \\
T stage & 0.017 & 0.647 & 0.453 & 0.926 \\
Differentiation & 0.958 & 0.993 & 0.771 & 1.279 \\
p53 & 0.115 & 0.714 & 0.470 & 1.085 \\
Ki-67 & 0.020 & 1.624 & 1.080 & 2.442 \\
SLC7A11 & 0.006 & 1.822 & 1.187 & 2.799 \\
\hline
\end{tabular}

Significance is indicated at $\mathrm{P}<0.05$ or $\mathrm{P}<0.01$, thus showing that there is a statistically significant correlation. Correlation is significant at a level of $<0.01$. LSCC, laryngeal squamous cell carcinoma; CI, confidence interval; SLC7A11, solute carrier family 7, membrane 11; Sig., significance.

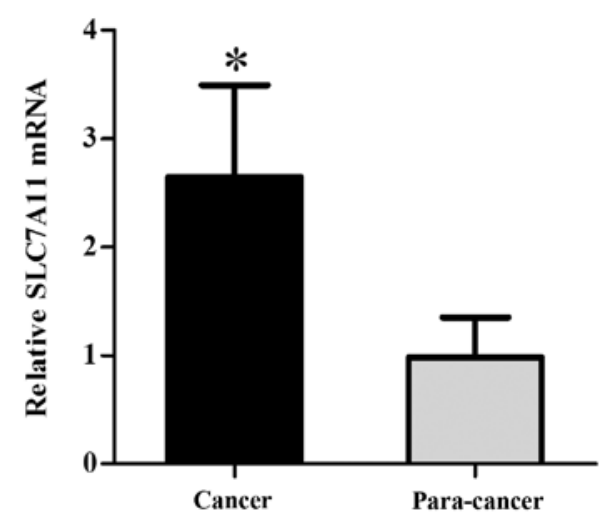

Figure 2. SLC7A11 mRNA levels in cancer tissues and in para-cancer tissues. The relative SLC7A11 mRNA levels were significantly higher in cancer tissues than that in para-cancer tissues $\left(n=30 ;{ }^{*} \mathrm{P}<0.05\right)$. Each experiment was repeated three times. 
Table VII. Relationship between the expression of SLC7A11, Ki-67 and p53, and the prognosis of the postoperative LSCC patients.

\begin{tabular}{|c|c|c|c|c|c|c|c|c|c|c|}
\hline \multirow[b]{2}{*}{ Prognosis } & \multirow[b]{2}{*}{ Total no. } & \multicolumn{2}{|c|}{ SLC7A11 } & \multirow[b]{2}{*}{ P-value } & \multicolumn{2}{|c|}{ Ki-67 } & \multirow[b]{2}{*}{ P-value } & \multicolumn{2}{|c|}{ p53 } & \multirow[b]{2}{*}{$\mathrm{P}$-value } \\
\hline & & + & - & & + & - & & + & - & \\
\hline Recurrence & 116 & 72 & 44 & 0.03 & 65 & 51 & 0.016 & 33 & 83 & 0.925 \\
\hline Non-recurrence & 211 & 105 & 106 & & 89 & 122 & & 59 & 152 & \\
\hline Total number & 327 & 177 & 150 & & 154 & 173 & & 92 & 235 & \\
\hline
\end{tabular}

SLC7A11, solute carrier family 7, membrane 11; LSCC, laryngeal squamous cell carcinoma.
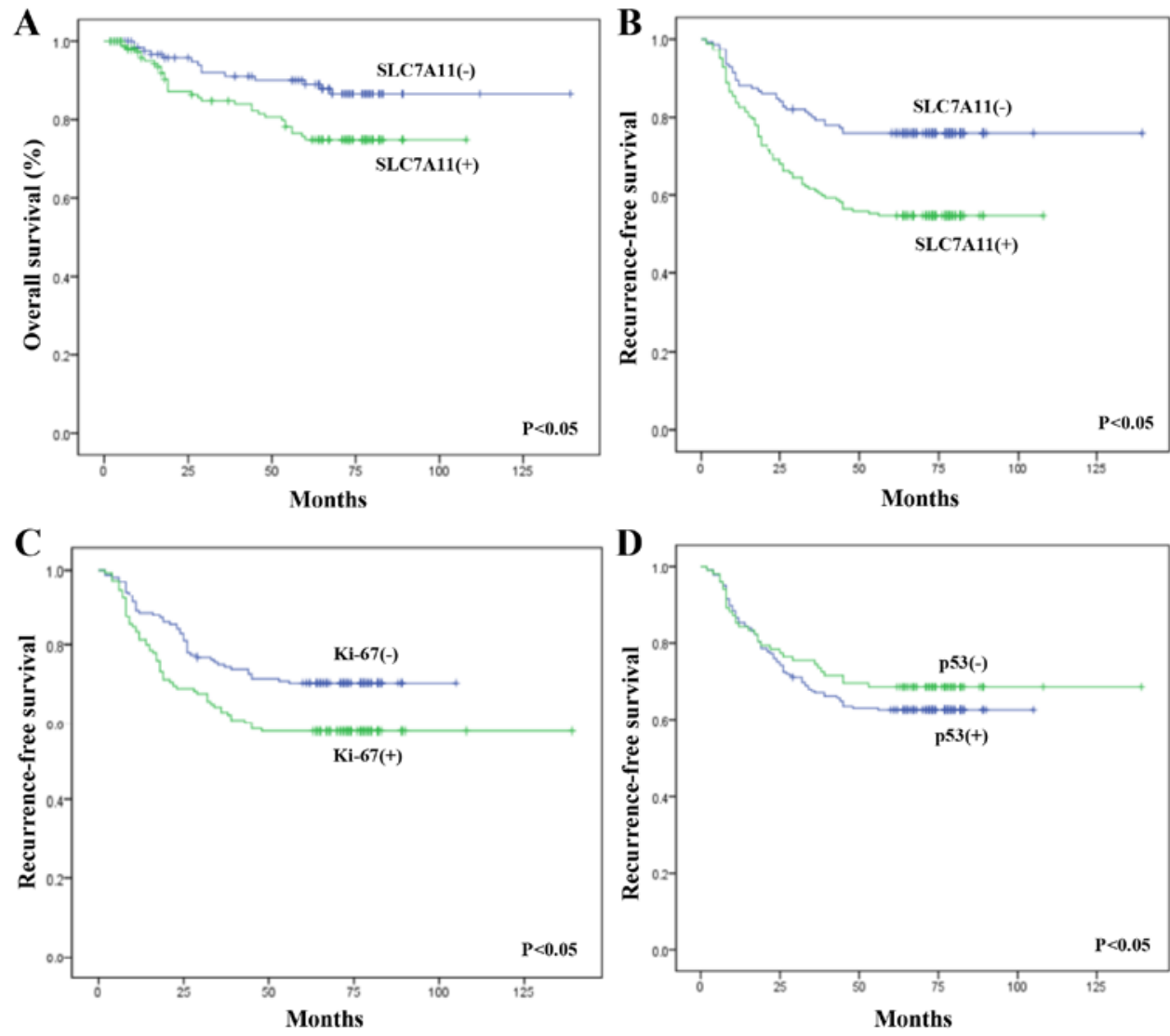

Figure 3. Kaplan-Meier plots for overall survival (OS) and recurrence-free survival (RFS). (A) The Kaplan-Meier plots indicated that LSCC patients with SLC7A11-positive expression were associated with poorer overall survival (OS). (B and C) Patients with SLC7A11-positive or with Ki-67-positive (belonging to high-risk group) were associated with poorer recurrence-free survival (RFS). (D) Whereas, there was no significant statistical difference in p53 expression between the recurrent and non-recurrent groups of the postoperative laryngeal squamous cell carcinoma (LSCC) patients.

were further assessed by qRT-PCR. As shown in Fig. 2, the levels of SLC7A11 mRNA transcription were significantly higher in the carcinomatous tissue than in the pericarcinomatous tissue (Fig. 2). GAPDH was regarded as an internal reference. For the homogenization process, each sample was analyzed by the $\Delta \Delta \mathrm{Ct}$ value. $\Delta \mathrm{Ct}=\mathrm{SLC7A} 11 \mathrm{mRNA}$ copy number/GAPDH mRNA copy number $(\mathrm{n}=30)(\mathrm{P}=0.021, \mathrm{P}<0.05)$. The graph was generated by GraphPad Prism software.

SLC7A11 is a prognostic factor for LSCC. To investigate whether SLC7A11 was a prognostic factor for LSCC, Cox regression and Kaplan-Meier analysis were performed to evaluate OS and RFS. Cox regression analysis confirmed that the expression levels of SLC7A11, Ki-67 and T stage were prognostic factors for laryngeal cancer (Table VI). The OS was significantly worse in patients with SLC7A11-positive tumors than that in patients with SLC7A11-negative tumors $(\mathrm{P}<0.05)$. Furthermore, Kaplan-Meier analysis confirmed that the SLC7A11 expression rate was $62.1 \%(72 / 116)$ and $49.7 \%(105 / 211)$ in the recurrent and non-recurrent groups of the postoperative LSCC patients, respectively, with a statistically significant difference $(\mathrm{P}<0.05)$. Meanwhile, the expression rate of Ki-67 in these two groups was $56.0 \%(65 / 116)$ and $42.2 \%(89 / 211)$, respectively, and this difference was also statistically significant $(\mathrm{P}<0.05)$. The positive rates of p53 expression were $28.4 \%$ (33/116) and 27.9\% (59/211) in the recurrent and non-recurrent groups of the postoperative 
A

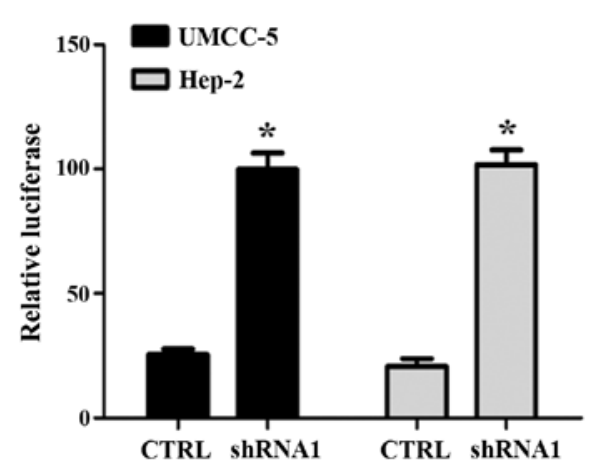

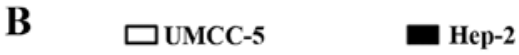

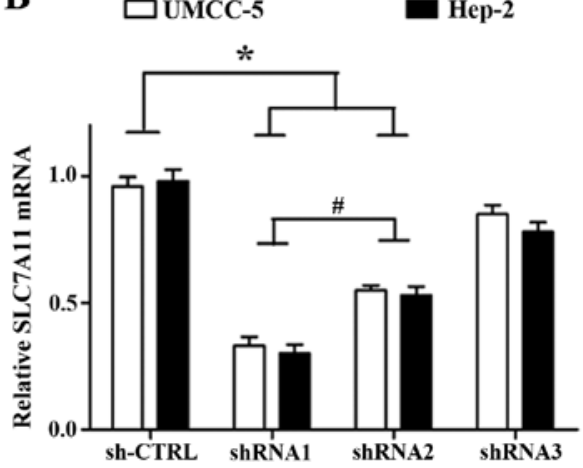

C
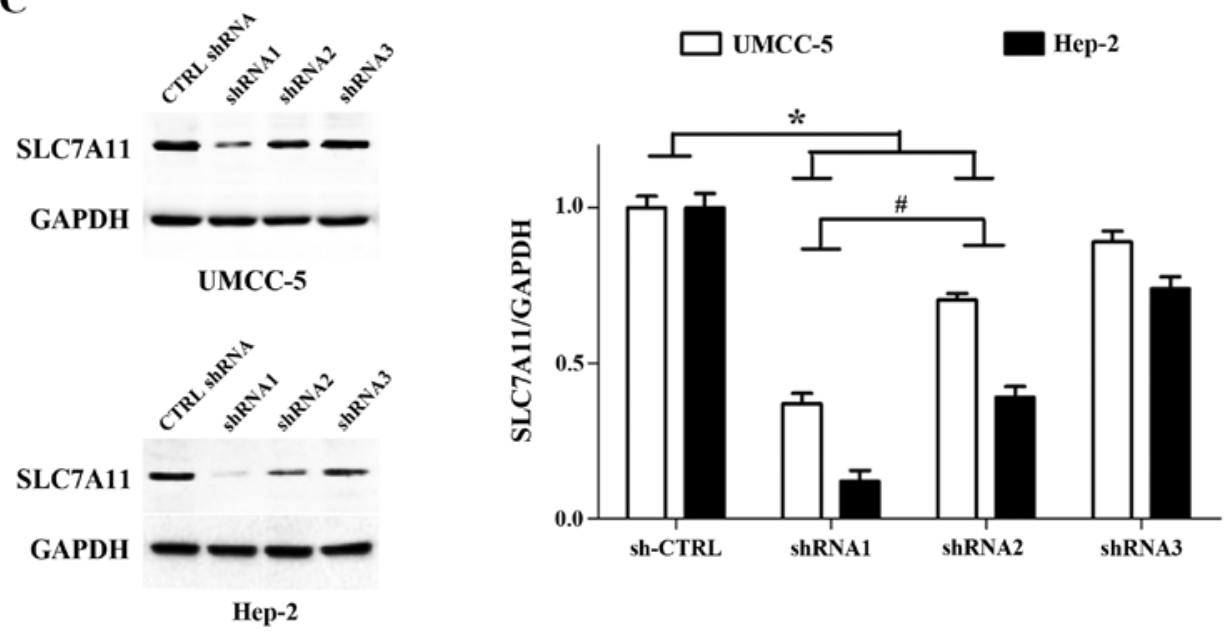

Figure 4. SLC7A11 expression is suppressed by SLC7A11-shRNAs in UMCC-5 and Hep-2 cells. (A) The luciferase activity was significantly higher in the SLC7A11-shRNA1 transfection group than that in the control group (untransfected virus group), mean $\pm \mathrm{SD}, \mathrm{n}=3$; ${ }^{*} \mathrm{P}<0.05$. The data from three independent experiments. (B) The mRNA levels of SLC7A11 in the UMCC-5 and Hep-2 cells were decreased in the SLC7A11-shRNA1 and SLC7A11-shRNA2 group more than that in the SLC7A11-shRNA3 and the sh-CTRL group by RT-PCR, mean \pm SD, $n=3 ;{ }^{*} \mathrm{P}<0.05$ (compared with the sh-CTRL group). The data from three independent experiments. (C) Compared with the SLC7A11-shRNA3 and the sh-CTRL groups, the protein levels of SLC7A11 were decreased in the SLC7A11shRNA1 and SLC7A11-shRNA2 groups. The quantified intensity of the protein bands is shown as the ratio of SLC7A11/GAPDH for different groups (n=3). Values are expressed as the mean $\pm \mathrm{SD} ;{ }^{*} \mathrm{P}<0.05$ (compared with the sh-CTRL group). The mRNA and protein levels of SLC7A11 were significantly inhibited in SLC7A11-shRNA1 compared with the SLC7A11-shRNA2 group $\left({ }^{\#} \mathrm{P}<0.05\right)$. The data were obtained from three independent experiments.

LSCC patients, respectively, with no statistically significant difference (P>0.05) (Table VII; Fig. 3).

SLC7A11 expression is suppressed by SLC7A11-shRNAs in UMCC-5 and Hep-2 cells. To observe the role of SLC7A11 on the growth of LSCC cells, we used SLC7A11-shRNAs (shRNA1, shRNA2 and shRNA3) to suppress the expression of SLC7A11 in UMCC-5 and Hep-2 cells. First, in order to show that the virus could be successfully transfected into the UMCC-5 and Hep-2 cells, we used SLC7A11-sh-RNA1 for luciferase experiments. As expected, the luciferase activity was significantly higher in the SLC7A11-shRNA1 transfection group than that in the control group (untransfected virus group) $(\mathrm{P}<0.05)$ (Fig. 4A), indicating the high efficiency and stability of the transfection. Furthermore, in order to demonstrate which of the three shRNAs (shRNA1, shRNA2 and shRNA3) had the most efficient function, we used PCR and western blotting. The mRNA levels of SLC7A11 were decreased in the SLC7A11-shRNA1 and SLC7A11-shRNA2 groups, more than that in the SLC7A11-shRNA3 and the sh-CTRL groups by RT-PCR (Fig. 4B). The protein levels of
SLC7A11 were determined by western blot assays and normalized for GAPDH. Compared with the SLC7A11-shRNA3 and the sh-CTRL groups, the protein levels of SLC7A11 were decreased in the SLC7A11-shRNA1 and SLC7A11-shRNA2 groups (Fig. 4C). The quantified intensity of protein bands is shown as the ratio of SLC7A11/GAPDH for the different groups $(n=3)$. Values are expressed as the mean $\pm S D, P<0.05$ (compared with the sh-CTRL group) (Fig. 4C). Finally, the mRNA and protein levels of SLC7A11 were significantly inhibited in the SLC7A11-shRNA1 group compared with the SLC7A11-shRNA2 group ( $\mathrm{P}<0.05$; Fig. $4 \mathrm{~B}$ and $\mathrm{C}$ ), and thus we selected SLC7A11-shRNA1 for the next related experimental research.

The effect of SLC7A11 knockdown on the proliferation of UMCC-5 and Hep-2 cells by MTT assay. The MTT assay revealed that downregulation of SLC7A11 markedly inhibited the growth of UMCC-5 and Hep-2 cells. The MTT assay indicated that cell proliferation was decreased more in the sh-RNA group than that in the sh-CTRL group (Fig. 5). 
UMCC-5 cells

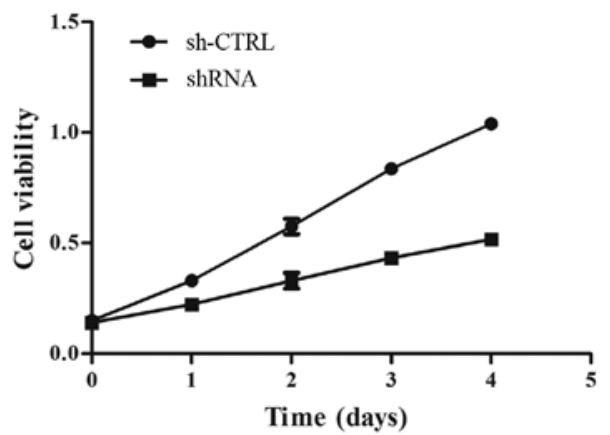

Hep-2 cells

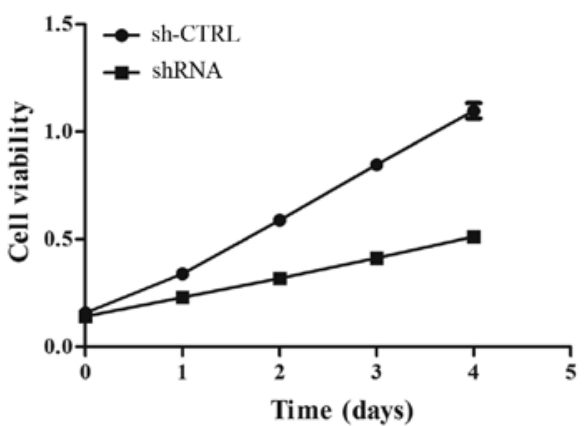

Figure 5. The effect of SLC7A11 knockdown on the growth of UMCC-5 and Hep-2 cells. After SLC7A11-shRNA transfection, the number of cells was counted at $24,48,72$ and $96 \mathrm{~h}$ by MTT assay. The MTT assay indicated that the cell proliferation was decreased more in the SLC7A11-shRNA group than in the sh-CTRL group, mean $\pm \mathrm{SD}\left(\mathrm{n}=3,{ }^{*} \mathrm{P}<0.05\right)$. The data were obtained from three independent experiments.

A
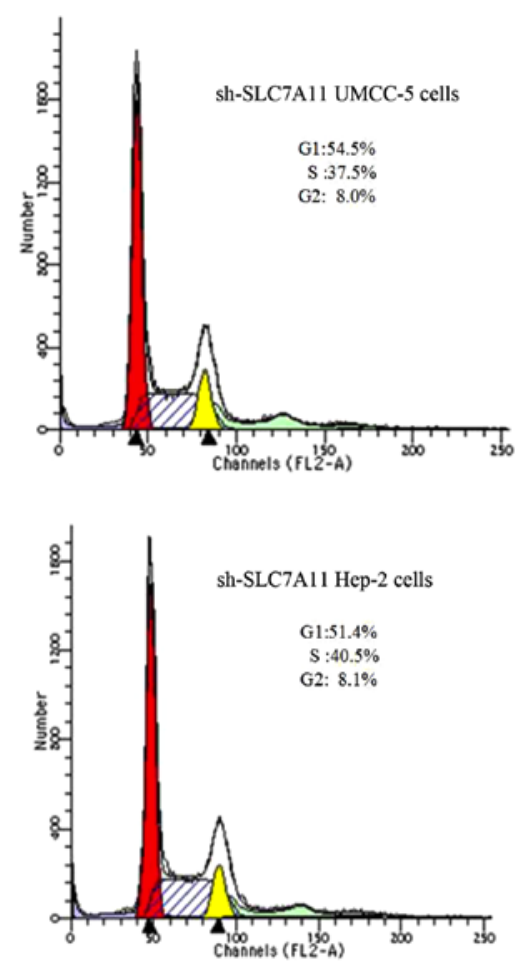

B

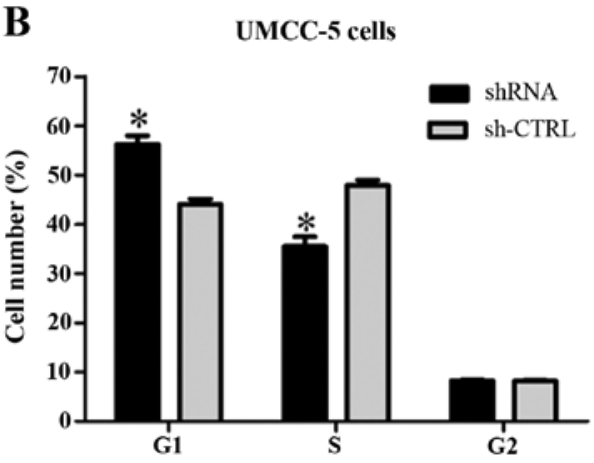

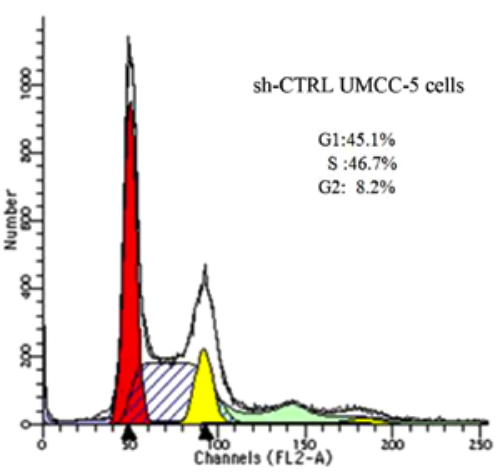

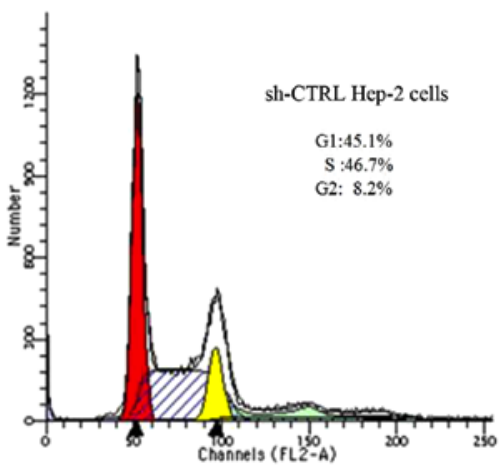

Hep-2 cells

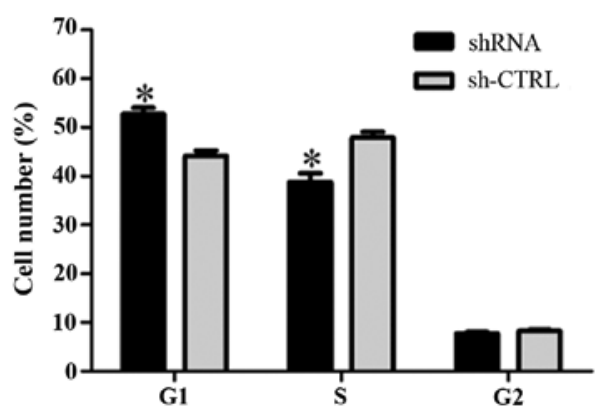

Figure 6. SLC7A11 controls the cell cycle progression of LSCC cells. (A) SLC7A11 knockdown induced cell cycle arrest at the G1 phase in the UMCC-5 and Hep-2 cells. Cells that had been transfected with SLC7A11-shRNA or sh-CTRL were stained with propidium iodide (PI) and analyzed using flow cytometry. (B) The cell percentage was indicated at different phases, mean $\pm \mathrm{SD}\left({ }^{*} \mathrm{P}<0.05\right)$. Each experiment was performed in triplicate and repeated three times.

SLC7A11 controls the cell cycle progression of LSCC cells. To investigate the mechanism underlying the promotion of cell proliferation of SLC7A11, we conducted knockdown experiments with SLC7A11-shRNA in UMCC-5 and Hep-2 
cells, and analyzed the effects of SLC7A11 on cell cycle progression. At $48 \mathrm{~h}$ after the shRNA transfection, the cells in the G1 phase were increased more in the shRNA-infected UMCC-5 and Hep-2 cells than in the sh-CTRL-infected UMCC-5 and Hep-2 cells (Fig. 6).

\section{Discussion}

System $\mathrm{X}_{\mathrm{c}}{ }^{-}$is a type of amino-acid transporter which is composed of a heavy subunit termed 4F2hc (SLC3A2) and a light chain subunit $\mathrm{xCT}$ (SLC7A11). Whereas SLC3A2 is a subunit common to several amino acid transporter systems, SLC7A11 is unique and responsible for importing the amino acid cystine into cells at a ratio of 1:1 counter-transport of glutamate (5). SLC7A11-mediated cystine transport for GSH synthesis plays a key role in the prevention of oxidative stress signaling that is strongly associated with cell proliferation and tumor growth (6). Notably, oxidative stress leads to the oxidative modification of proteins, lipids and DNAs and is thus thought to play an important role in many diseases. Furthermore, oxidative stress is particularly generated in cancer cells due to their relatively high metabolism (7). Thus, the activity of SLC7A11 is strongly associated with cancer cell proliferation and tumor growth (19).

Previous studies have detected that SLC7A11 was overexpressed in some types of solid tumor tissues or cells, associated with poor prognosis, and served as a biomarker for diagnosis $(20,21)$. Robert et al (11) suggested that SLC7A11-overexpressing tumors grew faster and shortened overall survival (OS). Guo et al (22) demonstrated that SLC7A11 expression was often increased in hepatocellular carcinoma (HCC) and was associated with poor prognosis in HCC patients. In agreement with previous studies, our results demonstrated that the expression of the SLC7A11 protein was increased in LSCC tissues as determined by immunochemistry and the mRNA expression levels of SLC7A11 in LSCC were also higher than that in pericarcinomatous tissue by RT-qPCR. Furthermore, The Kaplan-Meier plots indicated that LSCC patients with SLC7A11-positive expression were associated with poorer OS, and that the SLC7A11-positive tumors belonging to high-risk group were associated with poorer RFS. These results demonstrated a close association between SLC7A11 expression and undesirable prognosis, and suggested that SLC7A11 may be an important marker to predict prognosis in LSCC.

$\mathrm{Ki}-67$, the cell proliferation-associated antigen of antibody, has been explored as a prognostic or predictive marker in many malignant diseases (23). Pezzilli et al (23) suggested that the Ki-67 index was an precise and well-studied prognostic factor for pancreatic neuroendocrine neoplasms (PNENs) and it can be utilized for selecting patient candidates for surgical and particularly for non-surgical treatment. Shiozaki et al (10) demonstrated that SLC7A11-positive expression was positively correlated with the Ki-67 labeling index in human esophageal squamous cell carcinoma (ESCC). Our results from immunohistochemical examination revealed that the expression of Ki-67 was significantly higher in LSCC compared with those in precancerous lesions, and was positively correlated with the expression of SLC7A11.The log-rank test suggested that SLC7A11 (+)/Ki-67 (+) expression was correlated with RFS in postoperative LSCC patients. These results demonstrated that there was a close association between SLC7A11 expression and Ki-67 expression, and that SLC7A11-positive expression combined with Ki-67-positive expression had a dismal prognosis in LSCC.

p53 is an important tumor suppressor gene, which is the most commonly mutated gene in human cancers (24), and is stimulated by cellular stress such as ionizing radiation, hypoxia, carcinogens and oxidative stress. Although p53 mediated cell cycle arrest, senescence and apoptosis serve as critical barriers to cancer development. Recent studies revealed that other unconventional activities of p53 are also crucial for its tumorsuppressive function (25-27). Jiang et al (28) revealed that p53 regulates a type of cell death dubbed ferroptosis which belongs to a type of metabolic activity. By suppressing the expression of SLC7A11, p53 inhibits cystine uptake and sensitizes cells to ferroptosis, a non-apoptotic form of cell death $(28,29)$. In the present study, Spearman analysis revealed that the expression of $\mathrm{p} 53$ had a positive correlation with the expression of SLC7A11. We wondered whether SLC7A11 participates in the ferroptosis of LSCC and if the role of SLC7A11 can be regulated by p53 as well. Since ferroptosis can inhibit the growth of tumors $(30,31)$, our studies provide a research foundation to further explore and provide new insight into cancer therapy in LSCC.

On the basis of the results of the present study, we speculate that SLC7A11 may play important roles in tumorigenesis and tumor progression of LSCC. As RNA interference (RNAi) has been widely used as an experimental tool in studying gene function, to better explore the involvement of SLC7A11 in proliferation and progression of LSCC, RNAi targeting of SLC7A11 was used to knockdown the expression of SLC7A11 in in vitro experiments. The dysregulated cell cycle control of normal epithelial cells leading to uncontrolled proliferation is one of the major features of tumor progression. When the cells cease proliferation, the cell cycle may be arrested at the G1 check-points that assess cell size, extracellular growth signals, and DNA integrity $(32,33)$. In the present results, silencing of SLC7A11 significantly inhibited G1 to $S$ phase transition of Hep-2 and UMCC-5 cell lines, indicating that SLC7A11 shRNA inhibits cellular proliferation by inducing G1 phase cell cycle arrest. Similar results have been reported in human esophageal squamous cell carcinoma (10). By knockdown of SLC7A11 using siRNA, Shiozaki et al (10) observed that the expression of SLC7A11 affected the G1/S checkpoint and impacted the growth inhibition of ESCC cells. Furthermore, in the present study, the cell viability was assessed with the MTT method at 24, 48, 72 and $96 \mathrm{~h}$ after lentiviral transfection. We discovered that downregulation of SLC7A11 significantly inhibited the growth of Hep-2 and UMCC-5 cell lines. In conclusion, SLC7A11 may play an important role in tumor growth by regulating cell cycle progression and proliferation in the LSCC cell lines UMCC-5 and Hep-2.

In conclusion, to the best of our knowledge, this is the first study to demonstrate that SLC7A11 expression levels are upregulated in tumor tissues of LSCC patients. The expression levels of SLC7A11 can be used to distinguish LSCC from precancerosis or laryngeal benign tumors, and the overexpression of SLC7A11 in LSCC is correlated with laryngeal cancer 
recurrence and poor survival after surgery. Moreover, a functional study revealed that SLC7A11 plays a carcinogenic role in LSCC. In conclusion, the present study revealed that SLC7A11 may be a candidate novel molecular target for the diagnosis and prognosis in human LSCC, and targeting SLC7A11 may have clinical significance for the treatment of LSCC.

\section{Acknowledgements}

The present study was supported in part by the National Natural Science Foundation Of China (no. 81502493) and the Capital Health Research and Development of Special Project (no. 2014-2-2053).

\section{References}

1. Siegel RL, Miller KD and Jemal A: Cancer statistics, 2016. CA Cancer J Clin 66: 7-30, 2016.

2. Graboyes EM, Townsend ME, Kallogjeri D, Piccirillo JF and Nussenbaum B: Evaluation of quality metrics for surgically treated laryngeal squamous cell carcinoma. JAMA Otolaryngol Head Neck Surg 142: 1154-1163, 2016.

3. Marioni G, Marchese-Ragona R, Cartei G, Marchese F and Staffieri A: Current opinion in diagnosis and treatment of laryngeal carcinoma. Cancer Treat Rev 32: 504-515, 2006.

4. Mantsopoulos K, Psychogios G, Bohr C, Zenk J, Kapsreiter M, Waldfahrer F and Iro H: Primary surgical treatment of T3 glottic carcinoma: Long-term results and decision-making aspects. Laryngoscope 122: 2723-2727, 2012.

5. Lim JC and Donaldson PJ: Focus on molecules: The cystine/glutamate exchanger (System $\mathrm{x}_{\mathrm{c}}^{-}$). Exp Eye Res 92 . $162-163,2011$.

6. Lewerenz J, Hewett SJ, Huang Y, Lambros M, Gout PW, Kalivas PW, Massie A, Smolders I, Methner A, Pergande M, et al: The cystine/glutamate antiporter system $\mathrm{x}_{\mathrm{c}}{ }^{-}$in health and disease: From molecular mechanisms to novel therapeutic opportunities. Antioxid Redox Signal 18: 522-555, 2013.

7. Estrela JM, Ortega A and Obrador E: Glutathione in cancer biology and therapy. Crit Rev Clin Lab Sci 43: 143-181, 2006.

8. Koizume S and Miyagi Y: Lipid droplets: A key cellular organelle associated with cancer cell survival under normoxia and hypoxia. Int J Mol Sci 17: 1430-1453, 2016.

9. Bhutia YD, Babu E, Ramachandran S and Ganapathy V: Amino Acid transporters in cancer and their relevance to "glutamine addiction': Novel targets for the design of a new class of anticancer drugs. Cancer Res 75: 1782-1788, 2015.

10. Shiozaki A, Iitaka D, Ichikawa D, Nakashima S, Fujiwara H, Okamoto K, Kubota T, Komatsu S, Kosuga T, Takeshita H, et al: $\mathrm{xCT}$, component of cysteine/glutamate transporter, as an independent prognostic factor in human esophageal squamous cell carcinoma. J Gastroenterol 49: 853-863, 2014.

11. Robert SM, Buckingham SC, Campbell SL, Robel S, Holt KT, Ogunrinu-Babarinde T, Warren PP, White DM, Reid MA, Eschbacher JM, et al: SLC7A11 expression is associated with seizures and predicts poor survival in patients with malignant glioma. Sci Transl Med 7: 289ra86, 2015.

12. Okuno S, Sato H, Kuriyama-Matsumura K, Tamba M, Wang H, Sohda S, Hamada H, Yoshikawa H, Kondo T and Bannai S: Role of cystine transport in intracellular glutathione level and cisplatin resistance in human ovarian cancer cell lines. Br J Cancer 88: 951-956, 2003.

13. Lewerenz J, Maher $\mathrm{P}$ and Methner A: Regulation of $\mathrm{xCT}$ expression and system $x_{\mathrm{c}}{ }^{-}$function in neuronal cells. Amino Acids 42: 171-179, 2012.
14. Lo M, Ling V, Low C, Wang YZ and Gout PW: Potential use of the anti-inflammatory drug, sulfasalazine, for targeted therapy of pancreatic cancer. Curr Oncol 17: 9-16, 2010.

15. Timmerman LA, Holton T, Yuneva M, Louie RJ, Padró M, Daemen A, Hu M, Chan DA, Ethier SP, van 't Veer LJ, et al: Glutamine sensitivity analysis identifies the $\mathrm{xCT}$ antiporter as a common triple-negative breast tumor therapeutic target. Cancer Cell 24: 450-465, 2013.

16. Ma MZ, Chen G, Wang P, Lu WH, Zhu CF, Song M, Yang J, Wen S, Xu RH, Hu Y, et al: Xc- inhibitor sulfasalazine sensitizes colorectal cancer to cisplatin by a GSH-dependent mechanism. Cancer Lett 368: 88-96, 2015.

17. Wang R, Guo Y, Ma H, Feng L, Wang Q, Chen X, Lian M, Wang H and Fang J: Tumor necrosis factor superfamily member 13 is a novel biomarker for diagnosis and prognosis and promotes cancer cell proliferation in laryngeal squamous cell carcinoma. Tumour Biol 37: 2635-2645, 2016.

18. Stefanowicz-Hajduk J, Sparzak-Stefanowska B, KrauzeBaranowska M and Ochocka JR: Securinine from Phyllanthus glaucus induces cell cycle arrest and apoptosis in human cervical cancer HeLa cells. PLoS One 11: e0165372, 2016.

19. Anderson CL, Iyer SS, Ziegler TR and Jones DP: Control of extracellular cysteine/cystine redox state by HT-29 cells is independent of cellular glutathione. Am J Physiol Regul Integr Comp Physiol 293: R1069-R1075, 2007.

20. Lo M, Wang YZ and Gout PW: The $x_{c}{ }^{-}$cystine/glutamate antiporter: A potential target for therapy of cancer and other diseases. J Cell Physiol 215: 593-602, 2008.

21. Gout PW, Buckley AR, Simms CR and Bruchovsky N: Sulfasalazine, a potent suppressor of lymphoma growth by inhibition of the $\mathrm{x}_{\mathrm{c}}{ }^{-}$cystine transporter: A new action for an old drug. Leukemia 15: 1633-1640, 2001.

22. Guo W, Zhao Y, Zhang Z, Tan N, Zhao F, Ge C, Liang L, Jia D, Chen T, Yao M, et al: Disruption of xCT inhibits cell growth via the ROS/autophagy pathway in hepatocellular carcinoma. Cancer Lett 312: 55-61, 2011.

23. Pezzilli R, Partelli S, Cannizzaro R, Pagano N, Crippa S, Pagnanelli $\mathrm{M}$ and Falconi $\mathrm{M}$ : Ki-67 prognostic and therapeutic decision driven marker for pancreatic neuroendocrine neoplasms (PNENs): A systematic review. Adv Med Sci 61: 147-153, 2016.

24. Cheah PL and Looi LM: p53: an overview of over two decades of study. Malays J Pathol 23: 9-16, 2001.

25. Wang SJ and Gu W: To be, or not to be: Functional dilemma of p53 metabolic regulation. Curr Opin Oncol 26: 78-85, 2014.

26. Bieging KT and Attardi LD: Deconstructing p53 transcriptional networks in tumor suppression. Trends Cell Biol 22: 97-106, 2012.

27. Brady CA, Jiang D, Mello SS, Johnson TM, Jarvis LA, Kozak MM, Kenzelmann Broz D, Basak S, Park EJ, McLaughlin ME, et al: Distinct 553 transcriptional programs dictate acute DNA-damage responses and tumor suppression. Cell 145: 571-583, 2011.

28. Jiang L, Kon N, Li T, Wang SJ, Su T, Hibshoosh H, Baer R and $\mathrm{Gu}$ W: Ferroptosis as a p53-mediated activity during tumour suppression. Nature 520: 57-62, 2015.

29. Cao JY and Dixon SJ: Mechanisms of ferroptosis. Cell Mol Life Sci 73: 2195-2209, 2016.

30. Dixon SJ, Patel DN, Welsch M, Skouta R, Lee ED, Hayano M, Thomas AG, Gleason CE, Tatonetti NP, Slusher BS, et al: Pharmacological inhibition of cystine-glutamate exchange induces endoplasmic reticulum stress and ferroptosis. Elife 3: e02523, 2014.

31. Yu H, Guo P, Xie X, Wang Y and Chen G: Ferroptosis, a new form of cell death, and its relationships with tumourous diseases. J Cell Mol Med 21: 648-657, 2017.

32. Golubnitschaja O: Cell cycle checkpoints: The role and evaluation for early diagnosis of senescence, cardiovascular, cancer, and neurodegenerative diseases. Amino Acids 32: 359-371, 2007.

33. Visconti R, Della Monica R and Grieco D: Cell cycle checkpoint in cancer: a therapeutically targetable double-edged sword. J Exp Clin Cancer Res 35: 153, 2016. 